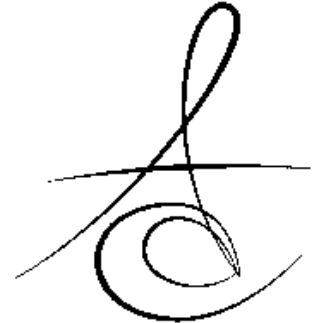

Makale Kodu/Article code: 1258

Makale Gönderilme tarihi: 13.08.2013

Kabul Tarihi: 22.08.2013

\title{
NATAL VE NEONATAL DİŞLER
}

NATAL AND NEONATAL TEETH

Yrd. Doç. Dr. Tevfik DEMİRCí

Prof. Dr. Taşkın GÜRBÜZ*

\author{
Yrd. Doç. Dr. Fatih ŞENGÜL* \\ Arş. Gör. Dt. Nesrin SARUHAN ${ }^{* *}$
}

\section{ÖZET}

Oral kaviteye ilk süt dişlerinin sürmesi 6-9. aylarda gerçekleşmektedir. Doğumdan bu zamana kadar, genel gelişimde olduğu gibi ağız içerisinde de birçok değişiklik gerçekleşmektedir. Bu süreçte meydana gelen değişikliklerin etraflıca bilinmesi, çocuğa iyi bir dental bakım sağlanabilmesi için önem arz etmektedir. Dişlerin sürmesi genellikle kronolojik bir sırayı takip etse de istisnalar görülebilmektedir. Bu sıra dışı durumlardan birisi de doğumda ağızda bulunan natal dişler ve doğumdan sonraki ilk ay içerisinde süren neonatal diş/erdir. Natal ve neonatal dişler nadir olarak karşılaşılan dişlerdir ve ebeveyn ve aile hekimleri böyle bir durumda nasıl davranılacağını tam olarak bilmemektedir. Bu çalışmanın amacl, nadir karşılaşılan bir durum olan natal-neonatal dişler hakkındaki mevcut çalışmalardan önemli noktaların derlenmesi ve bu dişlerin tedavi yaklaşımları hakkında bilgi sunmaktır.

Anahtar Kelimeler: Natal dişler, neonatal dişler, riga-fede hastalığı

\section{ABSTRACT}

The normal eruption of the primary teeth especially begins at $6-9^{\text {th }}$ months of age. From delivery to this age a number of differences occur in the oral cavity as well as the general development of the infant. Comprehensive knowledge of dental needs occuring in this period is vital in order to provide sufficient oral care for the infant. Tooth eruption usually follows a chronological order with rare exceptions as natal teeth and neonatal teeth, teeth present at the time of birth and erupt within the following 30 days respectively. Natal and neonatal teeth are of rare incidence and parents and physicians have limited knowledge about management of these cases. The aim of this study was to review the important aspects of the literature about natal and neonatal teeth.

Key Words: Natal teeth, neonatal teeth, riga-fede disease

\section{Natal ve Neonatal Dişler}

Diş hekimliğinin mevcut prensiplerinden birisi, ağız sağlığını sürdürebilmenin bir yolu olarak yenidoğanlarda ilk yılda tam bir oral sağlık bakımı gerçekleştirmektir. Bu nedenle, bu yıl içerisinde oluşan dental gereksinimlerin bilinmesi, daha koruyucu yaklaşımların seçilmesi ve uygulanabilmesi açısından önemlidir. ${ }^{1}$ Doğumdan sonraki ilk yıl içerisinde çocuk gelişiminin birçok bileşeni bulunmaktadır. Bunlardan birisi de yaklaşık 6. ayda alt süt orta keserlerin sürmesidir. ${ }^{2}$ Dişler oral kaviteye genellikle belirli bir zaman sıralamasına göre sürmektedir. Bu sıra büyük ölçüde sabittir ve genetik, çevresel ve hormonal faktörlerin etkisiyle küçük değişiklikler gösterebilmektedir. ${ }^{3}$ Kızlarda ve erkeklerde 6-9. aylarda mandibular süt orta keser dişlerin genellikle sürdüğü, 36. ayda ise süt dişlerin sürmesinin tamamlandığı ifade edilmiştir. ${ }^{4}$ Bununla beraber nadir de olsa doğumda veya doğumdan sonraki 30 gün içerisinde süren dişler de bulunmaktadır. Bu dişlere; konjenital dişı, fetal diş, predecidual diş ve dentitia preacox (çok erken süren dişler) gibi çeşitli isimler verilmektedir. ${ }^{5}$ Sadece,

\footnotetext{
*Atatürk Üniversitesi, Diş Hekimliği Fakültesi, Pedodonti A.B.D

${ }^{* *}$ Atatürk Üniversitesi. Dis Hekimliăi Fakültesi. Aăız Dis ve Cene Cerrahisi A.B.D.
} 
dişlerin sürme zamanlarının dikkate alındığı ve doğumda ağızda bulunan dişlere natal dişs, doğumdan sonra bir ay içerisinde süren dişlere ise neonatal diş denildiği isimlendirme ${ }^{6}$ genel olarak kabul görmüş ve yaygın olarak kullanılmaktadır., 5-8

Natal ve neonatal dişler emzirme esnasında, aşırı mobil olmaları nedeniyle, yutulabilme veya aspire edilebilme riskleri dolayısıyla hem aile için hem de diş hekimi için önemlidir. ${ }^{1}$

\section{Prevalans}

Natal ve neonatal dişlerin prevalansı ile ilgili farklı popülasyonlarda farklı oranların rapor edildiği çalışmalar bulunmaktadır. ${ }^{1,9,10} \mathrm{Bu}$ dişlerin görülme sıklığı 1:2000 ile 1:3500 arasında belirtilmiştir ${ }^{11} \mathrm{Kız}$ larda ve erkeklerde görülme sıklığı ile ilgili literatürde farklı bilgiler bulunmaktadır. Bazı çalışmalarda kızlarda daha fazla görüldüğü belirtilirken ${ }^{6,7,12}$ bazı çalışmalarda farklılık olmadığı rapor edilmiştir. ${ }^{1,8,11,13}$ Bununla birlikte natal dişler neonatal dişlere oranla daha fazla görülmektedir. $8,11,14$

\section{Etiyoloji}

Natal ve neonatal dişlerin kesin etiyolojisi bilinmemektedir. Bu dişlerin varlığı ile ilgili olarak birçok teori öne sürülmüştür. Bunlardan bazıları:

- Beslenme eksikliği

- Annenin sağlık problemlerinden kaynaklanan hipovitaminoz

- Endokrin sistem bozuklukları ve

- Hamilelik süresince görülen böbrek iltihabı olarak ifade edilmiştir. ${ }^{11}$

Pitüiter bezlerin tiroid veya gonadların aşırı sekresyonu sonucu da oluşabileceği öne sürülmüştür. ${ }^{6}$ Konjenital sifiliz, prematür veya gecikmiş doğum, hamilelik süresince geçirilen ateşli hastalıklar, çiçek, şiddetli ateş gibi durumlar normal diş sürme sürecini etkileyebilir.6, 15 Ayrıca otozomal dominant geçişin ve genetik faktörün etken olabileceğini bildiren çalışmalar da bulunmaktadır. ${ }^{5,8,16,17}$

Bir diğer teori ise, gelişim süresince diş germinin alveol kemiği içerisinde anormal bir konumda olmasıdır. ${ }^{18,19}$ Ayrıca, natal ve neonatal dişler diş germ alanındaki osteoblastik aktivite ile de ilişkilendirilmiştir. ${ }^{20}$ Gladden ve ark ${ }^{21}$ Tayvan'daki çevre faciasından etkilenmiş 128 hastanın 13'ünde natal dişe rastlamışlardır. Anneleri Japonya Kyushu'da poliklorlu bifenil (PCB) zehirlenmesi geçiren 12 canlı doğumdan 2'sinde natal diş rapor edilmiştir. ${ }^{22}$ Fakat, bunun aksini bildiren bir çalışma da bulunmaktadır. ${ }^{23}$

Natal ve neonatal dişler birtakım sendrom ve gelişim bozuklukları ile birlikte de görülmüş ancak bir korelasyon ortaya koyulmamıştır. ${ }^{1}$ Bunlardan bazıları:

$>$ Down sendromu

$>$ Pierre Robin sendromu

$>$ Dudak damak yarıkları

$>$ Hiper IgE sendromu

$>$ Van der Woude sendromu

$>$ Patent ductus arteriosus

$>$ Pfeiffer sendromu

$>$ Goltz sendromu

$>$ Epidermolizis bulloza simpleks

$>$ Siklopia

$>$ Transient psödohipoparatiroidizm

$>$ Bifid tongue ve profound sensorinöral işitme kaybı

\section{Histolojik ve Klinik Karakteristik Özellikleri}

Natal ve neonatal dişler genellikle 2 adet görülse de 11 , 12 ve 14 adet natal diş rapor eden çalışmalar da bulunmaktadır. ${ }^{24-26}$ Genellikle en çok alt süt orta keserler etkilenmekte ve çift olarak görülmektedir. ${ }^{5,10}$

Genel itibariyle temel yapı normal olsa da minenin displastik olarak tanımlanan yapısının erken sürme ile ilişkili olduğu düşünülmektedir. Mine, kuronun sadece 2/3'ünü kaplamakla birlikte normal bir histolojik yapıya sahiptir. ${ }^{23,27-29}$ Nadiren minesiz dişlerle de karşılaşıldığı rapor edilmiştir. ${ }^{6,} 7$ Çocuğun yaşına göre minenin yapısı normaldir. Ancak prematür sürme nedeniyle mine tamamen kalsifiye olmadığı için kuron boyut olarak daha küçük ve sarı-kahverengi görünümdedir ve aşınmaya direnci düşüktür. Ayrıca, mine dentin bağlantısı düzensizdir. ${ }^{28,} 29$ Bu dişler klinik olarak, normal boy ve şekilde veya az gelişmiş ve kötü şekillenmiş, küçük, konik, sarı- kahverengi veya beyazımsı renkte olabilirler. ${ }^{30}$ Mine ve dentinin hipoplastik yapıda olmaları nedeniyle de kolaylıkla renklenebilirler. ${ }^{5}$

Neonatal dişler sürdüklerinde nispeten daha gelişmiş olmaları nedeniyle süt dişlerine daha benzer görünüm sergilemektedirler. Natal ve noenatal dişlerin kök oluşumlarının büyük ölçüde farklı olduğu rapor edilmiştir. ${ }^{8,} 27$ Ayrıca, kök gelişimi olmadığı veya çok az olduğu için bu dişler oldukça mobildir. ${ }^{31,32}$ 
Kuron dentini ve predentini yapı olarak normal görünürken servikale doğru dentin tübüllerinin azaldığı ve interglobüler boşlukların anormal hücre inklüzyonları nedeniyle düzensiz hale gelebildiği bildirilmiştir. ${ }^{8,28,33}$ Apikalde ise diş hereketlerine bağlı olduğu düşünülen osteodentin benzeri bir görünüm sergilemektedir. Mobilitenin, hertwig epitel kınını zedelediği ve bunun da dişin stabilizasyonunu ve kök gelişimini engellediği düşünülmektedir. ${ }^{34}$ Artmış mobilitenin, servikaldeki dentin ve sementte histolojik değişikliklere neden olduğu düşünülmektedir. 27, 28, 34

Bu dişlerde sement bulunmayabilir veya bulunduğu durumlarda değişik kalınlıklarda ve aselüler bir yapıda olup kuronun sevikal $1 / 3$ 'ünü kaplayabilmektedir. Pulpa yapısı normal görünüme sahiptir, pulpa odası ve kanallar geniş görünümdedir. ${ }^{27,28,35}$

\section{Ayırıcı Tanı}

Ağızda, doğumda var olan veya doğumdan sonraki birkaç gün içerisinde süren dişlerin, normal süt dişlerinin erken sürmesi sonucu olduğu ifade edilmiştir. Bu dişlerin süpernümerer olarak görülme oranı \%1-10 olarak bildirilmiştir. ${ }^{5}$ 31, 36, 37 Süpernümerer süt dişi ayıımını yapmak için radyografik muayene gereksiniminden bahsedilebilir. Ayrıca radyografik muayene kök gelişiminin seviyesini ve çevre yapıları da gösterecektir. Ancak bu durum sorgulanmalıdır. Natal dişlerin karıştııılabileceği inklüzyon kist türleri de bulunmaktadır. Epstein incileri, bohn nodülleri ve dental lamina kistleri bunlar arasındadır. Epstein incileri palatinal orta hatta, odontojenik olmayan, birkaç milimetre çapına ulaşabilen, kahverengi şişlikler olup birkaç ay içinde kendiliğinden iyileşebilirler. ${ }^{11}$

Yenidoğanda görülen gingival kist, dental lamina kisti veya bohn nodülleri olarak da adlandırlır. Tipik olarak alveol kenarında çoklu nodüller olarak ortaya çıkarlar, çoğu olguda kistler dejenere olur. Bu kistler mandibular ve maksiller kretlerin bukkal ve lingual yüzeylerinde bulunan minör müköz tükürük bezlerinin kalıntılarıdır. ${ }^{11,38}$

Epstein incileri ve Bohn nodüllerinin klinik görünüşleri benzerdir. Her iki yapı da küçük, beyaz-gri kabarı 0,5-3 $\mathrm{mm}$ çapında tedavi gerektirmeyen nodüllerdir. ${ }^{16}$

Dental lamina kistleri tek veya çoklu nodüllerdir. Alt ve üst çenede kretlerde görülür. Ayrıca yenidoğanın gingival kisti olarak da bilinir. Deskuame epitel dolu bir lümeni bulunur. Genellikle inflamatuar hücrelerle doludur. Diş oluşumundan sonra kalan dental lamina artıklarından oluştuğu düşünülmektedir. Büyük çoğunluğu, iki hafta-beş ay içerisinde oral kaviteye drene olur. ${ }^{39}$

Bununla birlikte, natal dişlerin epulis ve odontojenik hamartomalar ile ayrımı yapılmalıdır. Epulisler tümör benzeri sapsız dişeti uzantılarıdır. Neoplastik lezyonlardan daha reaktiflerdir. Hamartomlar ise tümör benzeri neoplazmların gelişme karakteristiğini göstermeden gelişip olgunlaşabilen lezyonlardır. ${ }^{11}$

\section{Komplikasyonlar}

Natal ve neonatal dişlerin varlığında; emzirme esnasında annede ağıı, meme uçlarında ülserasyon nedeniyle emzirmenin kesintiye uğraması, çocukta diş çevresindeki dokuların enflamasyonu, dilaltı bölgesinde ve lingual frenilumda, alt çene keserler bölgesinde natal-neo-natal diş varlığında, riga fede olarak adlandırılan ülserasyonlar, çocukta dişin mobilitesine bağlı olarak ağrı hissi veya dilaltı bölgesindeki lezyonlar nedeniyle çocuğun emmeyi reddetmesi gibi komplikasyonlar görülebilir. Şimdiye kadar bildirilen bir vaka olmamakla beraber aşırı mobilite veya kendiliğinden düşmesi sonucu aspire edilebileceğine dair bir endişe de bulunmaktadır. Bu komplikasyonların yanı sıra; ishal, ağız kenarından salya akması ve huzursuzluk gibi normal dişlenme dönemi komplikasyonları da görülebilir. Muhtemelen ataşman kaybına bağlı apse gelişiminin bildirildiği vakalar da rapor edilmiştir. ${ }^{11}$

Natal dişlerle ilgili yaygın komplikasyonlardan birisi, dilin uç kısmı veya ventral kısmında riga-fede olarak bilinen ülserasyonlardır. Tekrarlayan dil itmeleriyle oluşan riga-fede ülserasyonu, natalneonatal dişlerde oluşacağı gibi alt keserleri süren bebeklerde de görülebilir. ${ }^{11}$ Tekrarlayan travma, granüloma görünümünde genişlemiş bir fibröz kitle oluşturur. Ülserasyon nedeniyle oluşan ağrı çocukta; beslenme zorluğu, dehidratasyon ve huzursuzluğa sebep olabilir. ${ }^{29,40}$ Diğer sistemik problemlerin de eşlik ettiği hastalarda kanama problemi görülebilir. Mine yıkımı nedeniyle çürük oluşumu ve periapikal apse meydana gelebilir. Dudak-damak yarı̆ı̆ bulunan vakalarda naso-alveoler birleşimde problem oluşabilir. ${ }^{11}$

Enfekte natal dişi takip eden süt ve daimi dişlerde hipoplazi nedeniyle osteitis, daimi dişte

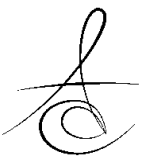


Atatürk Üniv. Diş Hek. Fak. Derg.

] Dent Fac Atatürk Uni

Supplement: 9, Yıl: 2014, Sayfa : 92-97
DEMİRCI, ŞENGÜL, GÜRBÜZ

SARUHAN mikrodonti görülebilir. ${ }^{13,41}$ Natal diş varlığında, belirsiz bir gelişimsel etki ile daimi dişlerde mesio-distal olarak yaygın bir küçüklük olacağı düşünülebilir. ${ }^{42,43}$

\section{Tedavisi}

Natal ve neonatal dişlerin tedavisinde dikkat edilmesi gereken çeşitli faktörler bulunmaktadır. Natal/neonatal diş, çocukta veya annede herhangi bir problem oluşturmuyorsa müdahale yapılmamalıdır. ${ }^{6}$

Natal/neonatal dişlerde kök oluşumunun gerçekleşip gerçekleşmeyeceğini tahmin etmek zordur. ${ }^{44}$ Bununla birlikte 4 ay stabil kalan dişlerin prognozunun iyi olduğu ifade edilmiştir. ${ }^{29}$ Farklı düşünceler olmakla beraber natal dişlerin ağızda tutulması süt dişi germinin erken sürmesiyle oluşacak yer kaybını önlemek için önerilmektedir. ${ }^{45-47}$

Eğer natal-neonatal diş, sürnümerer diş ise, mobilitesi fazlaysa, gelişimi zayıfsa, naso-alveoler yapıların birleşmesine müdahale ediyorsa veya apse teşekkül etmişse tedavi seçeneği çekimdir. ${ }^{11}$

Çekimden önce radyografi alınması dişin süt dişi veya sürnümerer diş ayrımını yapmak ve ebeveyni gelecekteki komplikasyonlar konusunda uyarmak için önerilebilir. Ancak bu yaş grubunda radyografi alınması sorgulanmalıdır.

Daimi diş germlerine çekim sırasında zarar verilmemesi adına natal-neonatal dişlerin mümkün olduğunca ağızda tutulması önerilmektedir. Karaciğerde $\mathrm{K}$ vitamini, protrombin üretimi için önemli olduğundan ve çocuk on günlük oluncaya kadar kommensal florası tamamen oluşmadığından, eğer rutin postnatal enjeksiyonu yapılmamışsa çekim öncesi çocuğa 0,5-1,0 mg IM, K vitamini takviyesi yapılması gereklidir. ${ }^{46}$ Hemofili açısından diğer kan değerleri de incelenmelidir. ${ }^{47}$

Çekim sırasında lokal anestezi uygulama tercihi hekime bağlıdır. Çekim sırasında bir boğaz tamponu kullanılmalıdır. Çekimden sonra dental papilla hücrelerinin gelişimine devam edip odontojen kalıntılar oluşturmasını engellemek amacıyla, çekim soketinin küretajı önerilmektedir.1,11,48 Eğer küretaj uygulanacaksa yeterli anestezi sağlanması adına lokal anestezi yapılması gerekmektedir. ${ }^{46}$ Yetersiz küretaj nedeniyle $\% 9.1$ rezidüel neonatal diş gelişimi, ${ }^{46,49}$ mikst kalsifiye hamartoma, ${ }^{50}$ sürmüş kalıntılar olarak pulpa polipi, ${ }^{51}$ çekim esnasında travmaya bağı olarak piyojenik granüloma ve periferik ossifying fibroma ${ }^{52}$ rapor edilmiştir.
Natal ve neonatal dişlerin bir diğer komplikasyonu olan riga-fede, çekim endikasyonu değildir. Tedavi seçenekleri arasında alt keserlerin insizal yüzeylerin möllenmesi, beslenme davranışlarının modifiye edilmesi, beslenme için kullanılan aracın (biberon vb.) değiştirilmesi, semptomların ilaçla tedavi edilmesi veya keserlerin insizal yüzeylerine kompozit uygulanması bulunmaktadır. ${ }^{40,53}$

Çoğu natal ve neonatal dişin minesi hipomineralize olduğundan ve nem kontrolünün yeterli olarak sağlanamamasından dolayı rezin bağlayıcı kullanımı sorgulanabilirdir ve materyalin inhale edilebilme ya da yutulma riski bulunmaktadır. Dilde hafif- orta irritasyon varlığında bu tedavi yeterli olabilir. Eğer travma nedeniyle ülsere olan bölge geniş ise insizal kenarlar düzeltilse bile emme esnasında dişler bu bölgeyi irrite etmeye devam edecek ve bu da iyileştirmeyi geciktirecektir. ${ }^{49,54}$ Lezyonun tekrarlayacağı da göz önünde bulundurulmalıdır. Konservatif yaklaşımların yetersiz olduğu durumlarda çekim veya lezyonun eksizyonu düşünülebilir.

Çocuk diş hekimleri, ebeveyni ve aile hekimlerini uygulayacağı tedaviler hakkında bilgilendirmeli, travma oluşumlarını önlemek için gerekirse çekim yapmalı ve gerekli konularda ebeveyni eğitmelidir. Çocuğun oral sağlık durumu peryodik olarak kontrol edilmelidir. Natal ve neonatal dişlerin tedavisi; komplikasyonları engellemek, erken tanı ve yeterli tedaviden oluşmaktadır.

\section{SONUÇ}

Natal-neonatal dişler yenidoğanda nadir görülen bir durumdur. En çok görülen dişler alt orta keserlerdir. Kesin etyolojisi bilinmemekle beraber en yaygın kabul edilen görüş kretlerde yüksek konumlanmış süt dişi germleri ve genetik faktörlerdir. En sık karşılaşılan komplikasyonlar emzirme ile ilişkilidir. Dişlerin süt dişi olması durumunda, yer kaybını önlemek için mümkün olduğunca dişin ağızda tutulması gerekmektedir. Tedavi, kapsamlı değerlendirmeler ışığında yapılmalı ve periyodik takip süreci çocuk diş hekimliği uzmanınca yürütülmelidir. 


\section{KAYNAKLAR}

1. Cunha RF, et al. Natal and neonatal teeth: review of the literature. Pediatric Dentistry. 2001; 23: 158-62.

2. Uzamis $M$, et al. Clinical and ultrastructural study of natal and neonatal teeth. The Journal of clinical pediatric dentistry. 1999; 23: 173.

3. Ramos SRP, Gugisch RC, and Fraiz FC. The influence of gestational age and birth weight of the newborn on tooth eruption. Journal of Applied Oral Science. 2006; 14: 228-32.

4. Falkner F. Deciduous tooth eruption. Archives of Disease in Childhood. 1957; 32: 386.

5. Zhu J and King D. Natal and neonatal teeth. ASDC journal of dentistry for children. 1995; 62: 123.

6. Massler $M$ and Savara BS. Natal and neonatal teeth: a review of twenty-four cases reported in the literature. The Journal of Pediatrics. 1950; 36: 349-59.

7. Allwright W. Natal and neonatal teeth: a study among Chinese in Hong Kong. Br Dent J. 1958; 105: 163-72.

8. Bodenhoff J and Gorlin RJ. Natal and neonatal teeth folklore and fact. Pediatrics. 1963; 32: 108793.

9. Machado de Almeida $C$ and Ribeiro Gomide $M$. Prevalence of natal/neonatal teeth in cleft lip and palate infants. The Cleft palate-craniofacial journal. 1996; 33: 297-9.

10. Leung AK. Natal teeth. Archives of Pediatrics \& Adolescent Medicine. 1986; 140: 249.

11. Markou I, Kana A, and Arhakis A. Natal and neonatal teeth: A review of the literature. Balkan Journal of Stomatology. 2012; 16: 132-40.

12. Anderson R. Natal and neonatal teeth: histologic investigation of two black females. ASDC journal of dentistry for children. 1982; 49: 300.

13. Singh S, et al. Reactive fibrous hyperplasia associated with a natal tooth. A Case Report. J Indian Sot Pedo Prev Dent. 2004; 22: 183-6.

14. El Khatib K, et al. [Natal teeth: apropos of five cases]. Revue de stomatologie et de chirurgie maxillo-faciale. 2005; 106: 325.

15. Boras VV, Zaini ZM, and Savage N. Supernumerary tooth with associated dentigerous cyst in an infant. A case report and review of differential diagnosis. Australian dental journal. 2007; 52: 150-3.
16. Cohen RL. Clinical perspectives on premature tooth eruption and cyst formation in neonates. Pediatric dermatology. 1984; 1: 301-6.

17. Hyatt HW. Natal Teeth Its Occurrence in Five Siblings. Clinical Pediatrics. 1965; 4: 46-8.

18. Baghdadi ZD. Riga-Fede disease: report of a case and review. Journal of Clinical Pediatric Dentistry. 2001; 25: 209-13.

19. Roberts MW, et al. Two natal maxillary molars: Report of a case. Oral Surgery, Oral Medicine, Oral Pathology. 1992; 73: 543-5.

20. Seminario AL and Ivancakova R. Natal and neonatal teeth. Acta Medica. 2004; 47: 229-33.

21. Gladen BC, et al. Dermatological findings in children exposed transplacentally to heat-degraded polychlorinated biphenyls in Taiwan. British journal of dermatology. 1990; 122: 799-808.

22. Miller RW. Congenital PCB poisoning: a reevaluation. Environmental health perspectives. 1985; 60: 211.

23. Alaluusua $S$, et al. Natal and neonatal teeth in relation to environmental toxicants. Pediatric research. 2002; 52: 652-5.

24. Goncalves FA, et al. Natal teeth: review of the literature and report of an unusual case. Braz Dent J. 1998; 9: 53-6.

25. Masatomi $Y$, Abe $K$, and Ooshima T. Unusual multiple natal teeth: case report. Pediatr Dent. 1991; 13: 170-2.

26. Portela MB, Damasceno L, and Primo LG. Unusual case of multiple natal teeth. Journal of Clinical Pediatric Dentistry. 2005; 29: 37-9.

27. Anneroth G, et al. Clinical, histologic and microradiographic study of natal, neonatal and pre-erupted teeth. European Journal of Oral Sciences. 1978; 86: 58-66.

28. Hals E. Natal and neonatal teeth: Histologic investigations in two brothers. Oral Surgery, Oral Medicine, Oral Pathology. 1957; 10(5): 509-21.

29. Kates G, Needleman $H$, and Holmes L. Natal and neonatal teeth: a clinical study. The Journal of the American Dental Association. 1984; 109: 441-3.

30. Anegundi RT, et al. Idiopathic gingival fibromatosis: a case report. Hong Kong Dental Journal. 2006; 3: 53-7. 
31. Galassi MS, Santos-Pinto L, and Ramalho LTO. Natal maxillary primary molars: case report. Journal of Clinical Pediatric Dentistry. 2005; 29 : 41-4.

32. Rusmah M. Natal and neonatal teeth: a clinical and histological study. The Journal of clinical pediatric dentistry. 1991; 15: 251.

33. Boyd J and Miles A. An erupted tooth in a cyclops foetus. British dental journal. 1951; 91: 173.

34. Southam J. The structure of natal and neonatal teeth. The Dental practitioner and dental record. 1968; 18: 423.

35. Spouge J and Feasby W. Erupted teeth in the newborn. Oral Surgery, Oral Medicine, Oral Pathology. 1966; 22: 198-208.

36. Buchanan $S$ and Jenkins CR. Riga-Fedes syndrome: Natal or neonatal teeth associated with tongue ulceration. Case report. Australian dental journal. 1997; 42: 225-7.

37. Hebling J, Zuanon A, and Vianna D. Dente Natal: A case of natal teeth. Odontologia Clínica. 1997; 7: 37-40.

38. Leung AK and Robson WLM. Natal teeth: a review. Journal of the National Medical Association. 2006; 98: 226.

39. Kumar A, Grewal H, and Verma M. Dental lamina cyst of newborn: A case report. Journal of Indian Society of Pedodontics and Preventive Dentistry. 2008; 26: 175.

40. Slayton RL. Treatment alternatives for sublingual traumatic ulceration (Riga-Fede disease). Pediatric Dentistry. 2000; 22: 413-21.

41. Kimoto S, et al. Hypoplasia of primary and permanent teeth following osteitis and the implications of delayed diagnosis of a neonatal maxillary primary molar. International Journal of Paediatric Dentistry. 2003; 13: 35-40.

42. Durning $P$ and MacLeod R. A neonatal tooth in a cleft palate baby: a complicating feature in neonatal orthopaedics--a case report. Journal of paediatric dentistry. 1988; 4: 27.

43. Marcushamer M, King D, and McCourt Jr JW. Microdontic teeth succedaneous to natal teeth: a report of two cases. Pediatr Dent. 1992; 14: 4001.

44. Sibert J and Porteous J. Erupted teeth in the newborn. 6 members in a family. Archives of Disease in Childhood. 1974; 49: 492.
45. Chow M. Natal and neonatal teeth. The Journal of the American Dental Association. 1980; 100: 2156.

46. Dyment $H$, et al. Residual neonatal teeth: a case report. J Can Dent Assoc. 2005; 71: 394-7.

47. Gardiner J. Erupted teeth in the newborn. Proceedings of the Royal Society of Medicine. 1961; 54: 504.

48. Southam J. Retained dentine papillae in the newborn. A clinical and histopathological study. British dental journal. 1968; 125: 534.

49. Ooshima T, et al. Eruption of tooth-like structure following the exfoliation of natal tooth: report of case. ASDC journal of dentistry for children. 1986; 53: 275.

50. Vergotine RJ, Hodgson B, and Lambert L. Pulp polyp associated with a natal tooth: case report. Journal of Clinical Pediatric Dentistry. 2009; 34: 161-3.

51. Muench M, Layton S, and Wright J. Pyogenic granuloma associated with a natal tooth: case report. Pediatric Dentistry. 1992; 14: 265.

52. Kohli K. Case Report Peripheral ossifying fibroma associated with a neonatal tooth: case report. Pediatric Dentistry. 1998; 20.

53. Padmanabhan MY, et al. Neonatal sublingual traumatic ulceration-case report \& review of the literature. Dental Traumatology. 2010; 26: 490-5.

54. Tsubone $\mathrm{H}$, et al. Clinico-pathological aspects of a residual natal tooth: a case report. Journal of oral pathology \& medicine. 2002; 31: 239-41.

\section{Yazışma Adresi:}

Yrd. Doç. Dr. Tevfik Demirci, Atatürk Üniversitesi, Diş Hekimliği Fakültesi, Pedodonti A.B.D., Erzurum, Turkiye Tel.: 0904422361828 Fax:090 4422360945 e-mail: tevfik2111@gmail.com) 